\title{
OS LIMITES POLÍTICOS DA DEMOCRACIA NA EDUCAÇÃO SUPERIOR BRASILEIRA DELINEADOS POR INTELECTUAIS DA ACADEMIA
}

\author{
Jỗo DOS REIS SILVA JR ${ }^{1}$
}

\author{
Recebido em 25/05/07
}

Avaliado em: 24/08/07

Doutor em Educação pela Pontifícia Universidade Católica de São Paulo PUC-SP), pós-doutorado em Sociologia Política pela Universidade Estadual de Campinas (Unicamp), professor e pesquisador do Departamento de Educação e do Programa de Pós-Graduação em Educação da Universidade Federal de São Carlos (UFSCar).

Resumo: Os processos de mudanças da educação superior brasileira nas últimas décadas ao lado do novo ordenamento jurídico do Estado Moderno, têm colocado em movimento transformações nas identidades das Instituições de Educação superior orientado por valores centrados na produtividade, na prestação de serviços e na hierarquia dos diferentes campos do saber. Este artigo objetiva explicitar estas características, relacionando-as com as orientações traçadas pelo Núcleo de Pesquisa sobre Ensino Superior (NUPES) da Universidade de São Paulo para a concretização da matriz teórica, política e ideológica baseada na eficiência do mercado, produzindo uma cultura pragmática e individualista, processos intensivos e extensivos de degradação do trabalho do professor no interior das Instituições.

Palavras-chaves: Educação Superior; Produção Teórica; Ordem Jurídica da Educação Superior

The Political Limits of Democracy in Brazilian

Higher Education Outlined by Intellectuals of the Academy

\begin{abstract}
The processes of change of Brazilian Higher Education in the last decades side by side with the new legal arrangement of the Modern State, have set in motion transformations in the identities of the Higher Education Institutions guided by values like the productivity, the rendering of services and the hierarchy of scientific fields of knowledge. This paper discusses these characteristics, relating them with the orientation traced by the Higher Education Research Nucleus (NUPES) at Sao Paulo University (USP) with the purpose of outlining the theoretical, ideological and political matrix based on market efficiency, producing a pragmatic and individualistic culture, provoking intensive and extensive processes of degradation of the professor's work in the Institution.
\end{abstract}

Key-words: Higher Education; Theoretical production; Higher Education Legal Order.

1 É autor de vários livros e muitos artigos e capítulos de livros no Brasil e no exterior. Dentre seus últimos livros publicados, destacam-se: Novas faces da educação superior no Brasil; reforma do Estado e mudança na produção, em co-autoria com Valdemar Sguissardi (Bragança Paulista: EDUSF, 1999, em sua 1. ${ }^{a}$ edição, e Bragança Paulista e São Paulo: EDUSF e Cortez: 2001, em sua 2 ${ }^{\mathrm{a}}$ edição); Trabalho e formação, em co-autoria com Jorge Luís Cammarano González (São Paulo: Xamã, 2001); Reformas do Estado e da educação no Brasil de FHC (São Paulo: Xamã, 2003); O institucional, a organização e a cultura da escola, em co-autoria com Celso Ferretti (São Paulo: Xamã, 2004) e Pragmatismo e populismo na educação superior no Brasil de FHC e LULA (São Paulo, 2005) Coordenador do Grupo de Pesquisa Economia Política da Educação, Cultura Escolar e Formação Humana do Programa de Pós-Graduação em Educação da UFSCar. E-mail: jr@power.ufscar.brou jr@pesquisador.cnpq.br 


\section{INTRODUÇÃO}

O imprevisto é uma espécie de deus avulso, Ao qual é preciso dar algumas ações de graças;

Pode ter voto decisivo na Assembléia dos acontecimentos. (Machado de Assis, Esaú e Jacó.)

A forma atual do capitalismo no Brasil produziu uma regulação social que procura a "nova institucionalidade", assentada na busca do consenso entre antagônicos, por meio de política de negociação e de uma brutal ofensiva ideológica contra tudo o que seja aparentado com soberania popular, e submetida à política econômica aceita desde o início dos anos noventa. Estruturou-se, institucionalmente, no mandato de Fernando Henrique Cardoso, por meio de várias emendas constitucionais e regulações inéditas, que buscaram legalizar uma série de facilidades facultadas ao capital, e tende a realizar-se e a adensar-se decisivamente no atual mandato presidencial.

A clareza, a horrenda visão da economia na condição de pura ideologia, nos faz lembrar um passeio pelo Estígio ciceroneado pelo Barqueiro Sombrio (Caronte) a quem se paga um óbolo para sofrer e purgar a miséria humana desta organização da vida reificada do ente social, que procura fazer do ser humano uma coisa divisível, quando ele não o é, e que busca fazê-lo específico, quando ele é genérico. Assim, o ser humano é doente e sente-se saudável por força da ideologia concretizada, de forma bestial, na economia da globalização, que estabelece a possibilidade do pacto social somente por meio da imposição de reformas em cada país, com a tradução de uma "nova institucionalidade", especialmente a da educação, por esta ser a única forma de socialização cujo ordenamento jurídico é monopólio de Estado. A instituição escolar, por exemplo, é considerada como instituição a ser reformada prioritariamente, conforme as exigências da economia globalizada, pois é capaz de oferecer a matriz teórica, política e ideológica para a reforma das demais instituições. As instituições educacionais, em suma, são consideradas fundamentais para a construção do "Plano Social Globalizado" (e desigual), nos termos da diferença que se observa, sem profundas investigações, entre, por exemplo, a Zona Leste e o Bairro dos Jardins, na Cidade de São Paulo, algo como a diferença entre Beverly Hill e o Bronx em Nova Iorque.

Histórica e necessariamente, a construção dos novos pactos sociais, neste caso nacionais, mas com unidade planetária, passa pela mudança da 
contradição entre as esferas indissociáveis e antagônicas públicas e privadas, em qualquer das atividades humanas, na sociedade civil ou no Estado, e nas instituições sociais públicas ou privadas.

Por outro lado, também é parte deste processo, a identificação ideológica entre Estado e o público, o que faz do entendimento das relações público-privadas um movimento complexo, quando se busca relacioná-las com o mercantil e, sobretudo, o estatal. Neste sentido, deve-se partir do princípio de que a liberdade e a igualdade são uma utopia iluminista e de que a propriedade privada e suas conseqüências são uma dura realidade na história do Capitalismo, especialmente no contexto da inserção do Brasil na imperial planetarização do capital, aqui, nunca entendido por meio do reducionismo economicista, mas, sobretudo, cultural, ainda que com limites e alcances qualitativos e quantitativos postos pela planetarização econômica.

A discussão sobre a cultura que embasa as relações sociais hoje e que lhes confere a racionalidade histórica do momento atual deve considerar, necessariamente, pelo menos, três amplos campos: a normatização institucional derivada do ordenamento jurídico do Estado Moderno, sua organização específica, que ali se origina, e a história específica das instituições da sociedade. Trata-se da natureza das instituições que, como o próprio substantivo indica, contribui para a instituição da cultura e que realiza, em parte, o pacto social em determinado período histórico, produzindo, em sua formação, aparentemente, o lugar privilegiado do ethos público no âmbito da sociedade civil. (SILVA JR; SGUISSARDI, 2005a).

Por outro lado, esta cultura tem escamoteado a contraposição estatal/público versus privado/mercantil. De acordo com Emir Sader, a esperteza da estratégia neoliberal consistiu em acentuar a suposta contraposição estatal-privado, em lugar da oposição real público-privado e, neste caso, em especial o pólo privado/mercantil (SADER, 2003, p. 3). Esse deslocamento seria extremamente favorável à estratégia neoliberal. Para que esta estratégia tenha êxito, demoniza-se o estatal como sendo o exclusivo reino da ineficiência, da burocracia, da corrupção, da opressão, da extorsão (de impostos) e da má prestação de serviços, e sacraliza-se o privado como sendo o reino exclusivo da liberdade, da criatividade, da imaginação e do dinamismo. Com esta contraposição, aparentemente correta, tirase de cena um termo essencial, isto é, o público, tal como concebido por Locke.

As políticas públicas passam, no país e no exterior, por um processo de mercantilização ancorado na privatização/mercantilização do espaço público - processo que já se punha de forma embrionária desde os 
primórdios do Capitalismo - e sob o impacto de teorias gerenciais próprias das empresas capitalistas, imersas na suposta autonomia ou real heteronomia do mercado, hoje coordenado por organismos multilaterais, que agem em toda extensão do planeta. O titular do Ministério da Reforma do Estado e da Administração Federal (MARE), Bresser Pereira, assim argumentava sobre a necessidade de uma "nova administração pública":

A abordagem gerencial, também conhecida como "nova administração pública", parte do reconhecimento de que os Estados democráticos contemporâneos não são simples instrumentos para garantir a propriedade e os contratos, mas formulam e implementam políticas públicas estratégicas para suas respectivas sociedades, tanto na área social quanto na área científica e tecnológica. E para isso é necessário que o Estado utilize práticas gerenciais modernas, sem perder de vista sua função eminentemente pública. (PEREIRA, 1996, p. 7).

O propósito do então ministro Bresser Pereira torna-se explícito nessa lógica da reforma do Estado, tanto no que se refere às instituições já citadas, quanto em relação à esfera pública: trata-se de introduzir, na esfera social, mediante a construção de um pacto social pragmático, a racionalidade gerencial capitalista e privada, que se traduz na redução da esfera pública ou na expansão da privada, mas, sobretudo, na acentuação da dimensão estatal/mercantil (e privado/mercantil) com sua racionalidade organizativa. (SILVA JR; SGUISSARDI, 2001, p. 75-77; SILVA JR; SGUISSARDI, 2005a p.16-17).

É com base nessa análise da realidade que contextualiza as políticas públicas recentes, em especial das políticas sociais, e na reflexão exigida pela materialidade histórica que envolve tanto a contradição público-privado, quanto a dimensão central e mercantil do Estado Moderno, que se pode compreender melhor a racionalidade político-administrativa dos governos FHC e dos dois anos e meio do Governo Lula.

É exatamente assim que a planetarização cultural expressa-se no Brasil por meio da criação da nova institucionalidade produzida a conta-gotas, que se torna a herança para Lula e o engessa, além de colocar o foco num governo, que fora de esquerda. A Carta ao Povo Brasileiro e a Proposta de um Pacto Social pragmático mostram claramente o quanto isso é, no mínimo, uma hipótese consistente.

Destacam-se, assim, dois processos ideológicos: a da identificação do Estado com público e outro protagonizado pela imprensa privada e pública brasileira - nosso melhor partido de direita no Brasil -, que insiste 
em pôr o foco nas legítimas críticas feitas ao governo Lula e ao Partido dos Trabalhadores (PT), e se esquece de apresentar questões que possam deslocar o foco para a saída de nossa crise, num contexto de representação social, no qual toda a sociedade frustra-se e intelectuais e jornalistas produzem a Cultura do Medo (SGUISSARDI; SILVA JR, 2005b). Medo de um regime político mais duro com apoio das forças armadas. Este quadro é produzido por esses agentes citados, que terão grande influência na proposta da lei de Reforma da Educação Superior, e obscurecem as alternativas da esquerda brasileira, facilitando o pensamento de direita, sedento por ganhar as ruas, como em 1964, com a famosa Marcha da Família em Favor da Propriedade Privada, com o apoio dos militares. A coragem para produzir a contradição entre a Cultura do Medo e a Busca da Liberdade (SGUISSARDI; SILVA JR, 2005b) deve ser assumida por nós, a brigar por uma educação superior autônoma, desvinculada do mercado, sem, contudo, deixar de contribuir para o crescimento econômico e para a produção de um pacto social conforme a planetarização. Mas, ao mesmo tempo, ser o lugar privilegiado da crítica institucional de seu tempo histórico, especialmente de seus próprios objetivos.

Antes, porém, é preciso apresentar outros atores sociais para completar nosso décor. O principal deles, que expressa o pensamento que orientou todo o processo da construção do atual Ordenamento Jurídico para Educação Superior, encontra-se dentro da Universidade de São Paulo: o ativo Núcleo de Pesquisa sobre Ensino Superior (NUPES), agora, incorporado pelo (NUPPs) Núcleo de Políticas Públicas da mesma universidade.

Deixando de existir o NUPES, a Lei de Reforma da Educação Superior perde paternidade, ainda que tenha sido resultado de uma discussão democrática levada a bom termo pela Sociedade Brasileira para o Progresso da Ciência (SBPC), tendo como Presidente o competente pesquisador internacional e melhor político Professor Ênnio Candotti. Esta associação, de passado honroso, põe-se como correia transportadora das propostas do governo Lula para a comunidade científica brasileira, legitimandoas e sendo ponto de apoio não somente teórico, mas, também, operacional, tal qual o NUPES; porém, sem a necessidade de produção teórica para formulação das políticas públicas para a educação superior.

Por outro lado, se a SBPC conseguiu aparentes avanços na terceira versão do anteprojeto de lei da reforma da Educação Superior e mais o aproximou, numa primeira análise do programa de governo democraticamente produzido nos primórdios dos anos 2000, comprou uma contenda com o setor privado mais organizado e com poder econômico e político superior ao da SBPC. Na proposta, que aí se encontra muito há das suges- 
tões da SBPC, expressas em muitas reuniões, com a participação do Ministro da Educação Fernando Haddad que, em função da contenda ainda em potência, vinha solicitar aos representantes da comunidade brasileira uma aliança, com a mediação da SBPC. A comunidade científica brasileira, em geral, parece não entender o que faz o setor privado como produção de conhecimento; para a grande maioria, o que é produzido neste setor não passa de mercadoria. Eis a questão que leva governo e a "comunidade científica brasileira" a se aproximarem de uma questão política que ainda não se pôs concretamente, encontrando-se em estado de latência. Nesse movimento, o que está em jogo é um sistema dual, como na educação secundária: as universidades públicas para as elites e as privadas, sem poderem gozar do mesmo status, para a massa, que compra sua forma de ser num contexto social perverso, nas universidades de segunda categoria. Em reuniões chegou-se a comentar até em nominalismo, como é o caso da França, onde existem Universités, Grandes Écoles, Les Écoles des Hautes Études. Uma IES privada, nestes termos, jamais poderia ser considerada como detentora do status da primeira instituição por não ter a densidade histórica de pesquisa, como a Universidade de São Paulo (USP), por exemplo.

Com o objetivo de manter ou produzir a referida hierarquia, o governo aliado com a grande maioria do setor público buscaria "brecar" o setor privado com a estratégia da avaliação dos alunos e das instituições, a que chamam "empresas", com critérios bem mais rigorosos, "bem mais apertados", especialmente nas demandas por credenciamento e nos pedidos de transformação, por exemplo, de Centro Universitário em Universidade. Nestes casos, chegou-se a sugerir a exigência de algo como quatro doutorados e igual ou maior número de mestrados.

Ao lado disto, teríamos uma política de homogeneização da qualidade do sistema federal e das redes estaduais da educação superior pública, com financiamento também público, mediante cooperação e assessoria dos grandes centros do eixo Rio de Janeiro/São Paulo. Parece que São Paulo quer construir a hegemonia, por meio da formação da elite brasileira, com sede no que seria a Atenas Brasileira: Universidades de São Paulo e do Rio de Janeiro.

Se tudo isso vier a se realizar, total ou parcialmente, ainda há muitas críticas a serem feitas.

As conseqüências dessa racionalidade tendencial são muitas, mas poderíamos destacar as mais interferentes na formação dos intelectuais brasileiros. Do exposto não é difícil observar: 1) um processo de homogeneização da produção científica no que se refere aos campos teóricos 
metodológicos, aos temas que tendem a ser priorizados nos financiamentos; 2) nesse processo de homogeneização, sob direção dos centros mais consolidados, haverá uma hierarquização de áreas do conhecimento e de instituições; 3) decorrente de tal tendência, pode-se vislumbrar uma outra - a maioria da produção crítica das ciências humanas e não aplicável de forma imediata será produzida por intelectuais formados nas instituições públicas, que poderão migrar para o setor privado, principalmente se vierem a se concretizar as medidas que se encontram nos baús dos gestores públicos do país e na iminência de uma reforma previdenciária, que aviltaria os direitos desses trabalhadores; 4) dos itens "1" e "2" pode-se depreender a enorme diferenciação institucional que poderá se realizar, dada a hierarquização no interior de uma homogeneização; 5) a maior parte do financiamento ficaria com os centros consolidados, aumentando a dependência dos novos cursos ou cursos de regiões fora do sudeste brasileiro; 6) ainda que indiretamente em função das normas do Programa de Qualificação Interinstitucional (PQI), no caso da pós-graduação ou de outro programa com orientação semelhante, a avaliação torna-se o instrumento fundamental para a implantação de um tipo de capacitação orientada pelos velhos catedráticos, posto que a CAPES financia e avalia simultaneamente, o que significa controle e regulação, e 7) a prestação de serviços ganhará um grande estímulo com os mestrados profissionais.

Diante de tais características, que se apresentam como tendências para a pós-graduação, as IES movimentar-se-ão no sentido de se organizarem nesses centros, seguindo o figurino dos consolidados; por outro lado, a cobrança da avaliação direcionada, como vimos, obrigará os alunos e docentes a serem produtivos e rápidos, impedindo-os desfrutar da cultura político-institucional do momento de sua titulação, no contexto da apropriação da cultura da instituição de educação superior, produzindo uma antecipação da perda, na forma de uma ansiedade antecipada.

Do ponto de vista docente, muda pouco, posto que, na avaliação do programa ou curso, ele deverá estar desenvolvendo pesquisa e publicando em periódicos determinados, para que seu programa ou curso seja bem avaliado, impedindo, muitas vezes, que o pesquisador possa dedicar-se a um estudo de longa duração, sem os produtos parciais requeridos pelo modelo de avaliação.

Isso traz para os programas e cursos de educação superior em geral um paradigma de gestão pragmático, assim como a ciência produzida pelos docentes e discentes também poderá orientar-se pelo mesmo paradigma, gerando, portanto, a antecipação da frustração e a intensidade da ansiedade, que ganham traços novos na Educação Superior, produzindo o que, 
juntamente com Valdemar Sguissardi, chamamos de cultura do medo (SGUISSARDI; SILVA JR, 2005b).

Há necessidade de cortes e recortes nos objetos de estudos e o estreitamento da reflexão que orientará suas análises, para viabilizar a pesquisa no tempo cronológico determinado para uma boa avaliação, ou, deveria dizer, uma boa nota. Essa é a situação da Educação Superior brasileira em potência e em ato realizado.

Já a pós-graduação tornou-se o locus privilegiado da produção da inovação tecnológica, das incubadoras de empresas, do desenvolvimento de parques de alta tecnologia, da produção de estratégias de inclusão social e digital, da produção de pedagogias adaptativas e instrumentais e da formação de intelectuais que configuram e reconfiguram os espaços público e privado com o objetivo de consolidar a nova forma de regulação social aqui aludida. Neste processo de reprodução alienada na cotidianidade, a indivisibilidade do homem põe-se, assim, como o objeto para sua divisibilidade. Em acréscimo, o novo ethos da pós-graduação limita o horizonte de possibilidades da reflexão do ser humano, reduzido pelo pragmatismo ao imediato e à predominância do gnosiológico, contrapondo-se, enquanto tal, como freio à reflexão. Penso que a globalização da cultura certamente levará a isso, se este anteprojeto for ao congresso e ali for aprovado, ainda que com algumas mudanças. Acrescento que $O$ Programa de Reestruturação e Expansão das Universidades Federais, na primeira minuta do Decreto-Lei na iminência de ser assinado, levava o título de Universidade Nova (UniNova).

Por outro lado, é necessário destacar as propostas do âmbito sindical, no contexto da racionalidade da governança de Lula. Qual base teórica pode ser antevista se aprovada a quarta versão do anteprojeto? A resposta é simples: a construção teórica do extinto NUPES, na inteligente estratégia política, como relatamos, deixando a paternidade das orientações teóricas da terceira versão do anteprojeto da Lei da Reforma da Educação Superior brasileira para a Sociedade Brasileira para o Progresso da Ciência, com seus bônus, mas, sobretudo com seus ônus. Assim, sem querer fazer uma análise detida do anteprojeto que, na minha hipótese, será detonado já na Câmara dos Deputados, mostro o que pretendia o governo FHC-LULA sobre a Educação Superior. O resultado dependerá da correlação de forças produzida pelo setor privado, de um lado, e o poder executivo, de outro, e seu trabalho de alianças por meio do Ministro da Educação, juntamente com setores da comunidade científica, ancorada no setor público. 


\section{O campo temático e teórico-metodológico e seu projeto político para a educação superior brasileira}

Palharini (1998) procura analisar os projetos de pesquisa em andamento no NUPES e os eventos nacionais e internacionais, mostrando as orientações e os objetivos da produção acadêmica do Núcleo, bem como sua relação com o campo político à época de sua fundação, em 1989, e da sua transformação em Núcleos de Apoio à Pesquisa (NAPs) da USP. Destaca-se que essa forma organizativa é diretamente ligada à Reitoria, passando ao largo dos departamentos, faculdades e institutos daquela Universidade. Isso parece indicar um alto grau de autonomia do NUPES e, ao mesmo tempo, uma relação direta com a Reitoria e com o Governador do Estado de São Paulo, ainda que respeitada a autonomia universitária, posto que muitos outros núcleos organizados conforme a estrutura "NAP" têm feito trabalho diametralmente oposto ao do NUPES.

$\mathrm{O}$ autor em que nos inspiramos desenvolve seu estudo e descreve os vários projetos e eventos, bem como apresenta os principais pesquisadores (Simon Schwartzman, Eunice Ribeiro Durham e Maria Helena Magalhães Castro). No período em que analisou a produção do NUPES, observou, com ênfase, que eles eram responsáveis por mais de 50\% do Núcleo. Por outro lado, deixou explícita a inserção desses intelectuais no campo político:

Ao final de 1989, Fernando Collor de Mello é eleito Presidente da República do Brasil e convida a ocupar a pasta do Ministério da Educação José Goldemberg, Reitor da USP que havia, por meio de portaria do ano anterior, dado existência ao NUPES. Acompanha-o nessa empreitada, Eunice Ribeiro Durham, que vem a ocupar a Secretaria do Ensino Superior e, logo após, cumulativamente, a Fundação CAPES. No Governo Fernando Henrique Cardoso, estando à frente do MEC o Ministro Paulo Renato, Eunice Ribeiro Durham passa a ocupar a Secretaria de Política Educacional, da qual se afastou, nessa mesma gestão, para assumir a condição de membro da Câmara de Ensino Superior do Conselho Nacional de Educação (CNE). Destacase também a participação em comissões e assessorias junto ao MEC de Simon Schwartzman ([em 1998], presidente do Instituto Brasileiro de Geografia e Estatística - IBGE), Maria Helena M. Castro, Jacques Schwartzman, Sérgio Costa Ribeiro, Elisa Wllnec, Cláudio Neiva, todos pesquisadores associados ao NUPES. (PALHARINI, 1998, p. 101). 
Diante do exposto até agora, é possível inferir, no mínimo, que o NUPES foi criado com características e objetivos claramente relacionados com um projeto político nacional para o Brasil, guiado por intelectuais que buscavam orientar, de determinada forma, os rumos do país. A produção acadêmica de pronto tornava-se a base para a elaboração das políticas que viriam desenhar o campo educacional desse nível de ensino, como se pode observar, mais recentemente, na reconfiguração da Educação Superior e em outras produções do NUPES, que se analisará mais à frente. Destaca-se, ainda, que o projeto político, desde a primeira campanha de FHC à Presidência da República, orientou a produção de um campo metodológico e temático que deu identidade acadêmica e política ao Núcleo. Dessa análise Palharini destaca o que chamou de "eixos norteadores" da produção do Núcleo, ainda que alerte para o fato de que uma produção oriunda de diferentes autores implica o risco de atribuir a alguns, aquilo que é hegemônico do discurso de outros. Por outro lado, é importante observar que os autores cujas obras orientam os principais pesquisadores do NUPES são, em sua grande maioria, estrangeiros e ligados a uma tradução de Weber por autores adeptos do Parsonismo ${ }^{2}$, mas que mantém relação orgânica, ainda que reducionista, com o vasto trabalho de Joseph BenDavid, grande inspirador de Simon Schwartzman, como ele próprio parece admitir em diversas referências.

Estes eixos consistiriam no campo temático complementado com "a carne da história", que o constrangia. São eles:

Em primeiro lugar, observa-se uma tendência a tomar as universidades estaduais paulistas como referencial de análise, embora o destinatário dessa análise tenda a ser o Sistema Federal de Ensino Superior (PALHARINI, 1998, p. 106).

Observa-se, aqui, um traço cultural que funda a institucionalidade da USP desde sua origem e se põe também para o NUPES. Diante dos objetivos de tomada de poder pelos paulistas, depois de fracassada a tentativa nos primeiros anos da década de 1930, Armando de Salles Oliveira, Interventor Federal do Estado de São Paulo, por meio do decreto ${ }^{\circ}{ }^{\circ} 6.283$, de 25 de janeiro de 1934, criava a USP. Dizia ele, que agora dispomos

$2[\ldots]$ a razão política da preeminência de Weber reside em ter sido um dos autores que serviu de base européia para o lançamento do funcionalismo norte-americano, teoria sociológica predominante no mundo depois da II Guerra Mundial até meados do anos de 1960. Do enorme magma de conhecimentos weberianos, os funcionalistas tomaram os que lhes eram mais favoráveis para o seu propósito de construir uma teoria universal. (MARSAL, 2002, p.13). 
[...] de instrumento do qual se prepararão as nossas elites dirigentes. Daqui continuarão a sair [...] homens que se destinam ao exercício da inteligência aplicada e que constituirão, sobretudo, os grupos de profissionais e do funcionalismo.

Continuava ele dizendo que tinha a intenção de fazer nascer "um verdadeiro cérebro, integrando a ciência e a técnica, para forjar uma elite intelectual capaz de orientar todas as classes sociais [...]”. Acrescentava, por fim, que "[...] a Universidade de São Paulo é a primeira semente do Brasil novo.” (CAMPOS, 1954; FÁVERO, 1980).

Os [...] seus principais autores partem da compreensão de mudança que se verificam no cenário econômico internacional, o grau de desenvolvimento econômico tende a definir a posição que cada país, nesse cenário, vai ocupar.

E, dessa forma, "considera imprescindível a constituição de modernas estruturas científicas que contribuam para modernizar a economia brasileira". Assim, de tal "modernização econômica derivar-se-ia, então, a melhoria das condições da vida da população." (PALHARINI, 1998, p. 107).

Completando as orientações ideológicas da criação do campo acadêmico e de um projeto político para o Brasil, Palharini (p. 107) depreende dos textos lidos sobre "a importância de um projeto de desenvolvimento que leve em consideração a necessidade de se buscar autonomia tecnológica, especialmente nas áreas de ponta." (p. 107) Vale destacar, a título de lembrança, os pressupostos das diretrizes curriculares para os cursos de graduação, ancorados na polissêmica noção de competência, da Lei de Inovação, bem como os Fundos Setoriais, que privilegiam centralmente tal "eixo norteador". Ou ainda, a criação de "centros de excelência" na educação superior que, além de privilegiar o eixo número dois, também se sustenta na velha crítica ao modelo humboldtiano de universidade, defendendo, com isso, a diferenciação das instituições de educação superior entre "universidades de ensino" e "universidades de pesquisa."

Ainda no plano geral, enfatiza a significativa expansão dos sistemas de ensino, e postula que a tendência atual é, cada vez mais, de ampliação da demanda pelo ensino superior", Ainda, "em decorrência da crise do Estado, verifica-se uma forte contração nos investimentos no ensino superior e em pesquisa, além de existirem limitações constitucionais para os gastos com educação. 
Tais "eixos norteadores" parecem orientar um projeto político para o país, que o insira na universalização do Capitalismo por meio da linear relação tão defendida por aqueles que vêem, na educação, a centralidade para a emancipação humana, isto é, desenvolvimento científico, aplicação tecnológica e o dinamismo, por intermédio da inovação tecnológica. Do que decorreria a necessidade de um cidadão trabalhador, cientista e toda sorte de profissionais que fossem competentes para se tornarem empregáveis e capazes de resolver problemas, sem questionar a razão de sua emergência na esfera social e do trabalho. Um novo ser social, que tem na categoria profissionalização todo espaço de mediação entre ele e a sociedade e entre a sociedade e o Estado: a sociedade puramente epistêmica. Finaliza Palharini (p. 108):

[...] tratar-se-ia, na concepção do NUPES, de se buscar uma maior eficiência na utilização dos recursos que estão disponíveis. Para tal, procura estimular a constituição de uma universidade racional. Inclusive porque constataria uma utilização irracional dos recursos por parte das IFES, em vários níveis, em especial no que se refere a distorções da carreira; à concessão indiscriminada do regime de dedicação exclusiva, como forma de compensação salarial; a privilégios corporativos; e à isonomia entre ativos e inativos etc Em decorrência, propõe-se um modelo centrado fundamentalmente na autonomia de gestão financeira, administrativa e pedagógica, a exemplo das estaduais paulistas. A autonomia universitária, portanto, é tratada como subordinada aos resultados do processo de avaliação a ser adotado.

As diversas conclusões a que chegamos ganham em clareza e consolida a hipótese produzida sobre o NUPES, quando se analisa os Documentos de Trabalho (DT), a partir de 1995. Tomamos como orientação o campo temático e o campo teórico-metodológico para escolhermos os DTs mais significativos para nossa reflexão. Destaca-se que, a partir dessa data, primeiro ano de mandato de Fernando Henrique Cardoso na Presidência da República do Brasil, os temas "ensino privado", "pós-graduação", "pesquisa na universidade pública", bem como, "organização acadêmica" e "gestão" se acentuam no rol de preocupações temáticas do NUPES, antecipando os diversos decretos e a própria Lei de Diretrizes e Bases para a Educação, no contexto de mercantilização das esferas sociais. Merece destaque, neste particular, a Educação Superior, no, agora, complexo espaço social, em que a diferenciação entre as instituições públicas, privadas strito sensu e comunitárias acirrou-se em face da acentuação da concorrência e 
do enorme mercado em que viera a se tornar o ensino superior, tanto para o capital industrial, como para o de serviços.

No DT 7/97, intitulado As Políticas Recentes para o Ensino Superior na América Latina, de autoria da então coordenadora do NUPES, Professora Eunice Ribeiro Durham, as preocupações em localizar o Brasil no processo de universalização do Capitalismo, por meio de mudanças no complexo espaço social do $3^{\circ}$ grau do Sistema Educacional brasileiro, surgem, neste texto, na análise comparativa das políticas para Educação Superior na América Latina, como um instrumento para contribuir com a normatização, então em curso para esse nível de ensino. Neste DT, Durham parece querer fazer a crítica ao modelo único de universidade, o que, segundo ela, estaria acontecendo em todos os países pesquisados (Argentina, Brasil, Chile, Colômbia e México).

Argumenta, que "os governos estão tentando superar as limitações do modelo de ensino superior vigente e enfrentar os novos problemas e tendências que ocorreram, em grande parte, à revelia das políticas anteriores (p. 12). No cerne sua crítica encontram-se as relações entre o setor público e sua relação com o Estado: essas deveriam alterar-se de forma profunda, "substituindo o sistema altamente centralizado e burocrático de controles governamentais associado ao financiamento incremental". Mantém a postura teórica do NUPES, como ressaltado anteriormente, afirmando, que tais ações deveriam ser realizadas articuladas com a "contenção dos gastos públicos, [com a] descentralização administrativa" e com a "introdução de processos de avaliação". Em seguida à análise afirmativa sobre os países analisados da América Latina, espelha-se nos países centrais: "A tendência é a mesma que se observa nos países desenvolvidos onde o ensino superior é financiado e controlado diretamente pelo Estado, como na Europa, [...] com a emergência do Estado avaliador" (p. 13).

Por fim arremata:

No conjunto, as reformas que estão sendo propostas contemplam uma série de medidas cujo espectro máximo envolveria:

Cobrança de anuidades como forma de captação de poupança privada para complementar as necessidades de financiamento do sistema;

Limitação de matrículas no setor público;

Implantação de mecanismos de avaliação da qualidade do ensino e produção científica;

Associação do financiamento à fixação de metas e/ou à alguma forma de avaliação de desempenho; 
Descentralização do sistema com simplificação dos controles burocráticos e concessão de maior autonomia administrativa às instituições (p. 13).

É interessante observar o que estaria nas entrelinhas da Professora Emérita da USP. Primeiramente, ela aceita um Estado avaliador diário, com contenção de gastos públicos para a educação e a cobrança de anuidades para, em seguida, afirmar uma descentralização que possibilitaria uma maior autonomia às instituições. Que descentralização e que autonomia pretende Durham para as instituições? Trata-se, ao que parece, de descentralizar o que fora centralizado pelo Estado, avaliar se as instituições cumprem suas metas, condicionar o contingenciamento das verbas públicas à avaliação e induzir ações das instituições para completarem seus orçamentos. Todo esse complexo de iniciativas pode ser chamado de uma "privatização controlada pelo Estado". No DT 8/96, intitulado A Pós-Graduação no Brasil - Problemas e Perspectivas, também da autoria de Durham, então presidente da Fundação CAPES (Coordenação de Aperfeiçoamento de Pessoal de Nível Superior) e Pesquisadora do NUPES, antecipa-se o que seriam as mudanças no sistema de avaliação da CAPES. A autora parte do pressuposto de que o sistema de pós-graduação brasileiro é formulado e posto em prática pelo Estado, "mas que sofre deformações profundas que ora enriquecem, ora empobrecem as determinações dos planejadores". Tais deformações teriam como conseqüências três aspectos marcantes na evolução dos estudos pós-graduados no país. Um primeiro se refere à estreita relação entre pesquisa e pós-graduação, invertendo o processo de criação dos programas de pós-graduação. "Para os docentes, a criação de um curso de pós-graduação passa a ser vista como um prérequisito para a constituição de um núcleo de pesquisa e não, como seria desejável, uma das suas conseqüências." (p. 15).

Outro aspecto da pós-graduação que distorcera a Educação Superior como um todo consistiria no fato de as instituições envidarem seus melhores esforços na criação de pós-graduação stricto sensu, o que teria acarretado uma desvalorização do lato-sensu, da iniciação científica e, conseqüentemente da própria graduação. Por outro lado, essa questão teria levado a duas outras consequiências: a) à definição do que fosse uma dissertação, que, em geral, aproximava-se de uma tese de doutorado, para que o curso de mestrado se consolidasse, com o fito da abertura do doutorado e b) à ênfase na formação para pesquisa científica e tecnológica para o todo o sistema de ensino superior no Brasil. Articulando tais aspectos próprios da pós-graduação brasileira, poder-se-ia concluir que esse nível da educa- 
ção superior teria concorrido para acentuação da diferenciação institucional e regional no país. "A maior parte do alunado e das titulações está localizada em pouco mais de meia dúzia de instituições, concentradas na Região Sudeste, refletindo a heterogeneidade do ensino superior", e, que segundo a autora, "permanece oculta nos embates ideológicos entre instituições públicas e privadas ou é escamoteada pelos interesses corporativos das universidades federais" (p. 16).

Sem embargo das procedentes críticas aos aspectos citados por Durham, sua conclusão faz água quando descamba para uma crítica ferrenha ao debate ideológico entre o público e o privado, como que a defender o segundo setor. Por outro lado, de forma muito inteligente, dá força ao argumento para ações em prol da diferenciação institucional já existente e para uma mudança/restrição da abertura de programas de pós-graduação, segundo modelo de avaliação atualmente vigente na CAPES hoje conhecido e que segue o ideário da produção acadêmica do NUPES, como se pode ao menos inferir da análise do DT anterior. Apesar de tal análise, no DT 09/98, Durham ratificará o ideário do NUPES, no que se refere à pesquisa na universidade pública:

O custo do ensino superior público no Brasil, hoje, é demasiado elevado para a qualidade que possui e o atendimento que fornece. É absolutamente essencial tornar o (sic) mais eficiente e de melhor qualidade, democratizando o acesso da população jovem ao ensino superior pela ampliação das matrículas nas instituições públicas, diversificação dos cursos oferecidos e pela introdução de cursos noturnos. Uma ação nesse sentido é essencial para legitimar e prestigiar a universidade perante a opinião pública, justificando o investimento de recursos públicos na educação superior. A mesma política de desregulamentação burocrática, autonomia de gestão e controle da qualidade do desempenho deve orientar a ação do Estado face às instituições privadas. Neste caso, o mecanismo de credenciamento periódico através de avaliações deve ser estabelecido. Avaliações desse tipo, quando tornadas públicas, orientam os consumidores e favorecem decididamente as melhores instituições do país em detrimento das piores (p. 34; grifo meu).

Conclui argumentando sobre a viabilidade desses instrumentos para melhoria da docência, pesquisa e extensão, posto já existirem, ainda que de forma fragmentada, "no conjunto do sistema de Ensino Superior, Ciência e Tecnologia”. A novidade residiria tão somente em integrá-los de for- 
ma sistematizada e orientada pelo ideário já delineado pelos pesquisadores do NUPES e, há anos, gestores de políticas públicas para a educação superior e para a ciência e tecnologia.

Do que se expôs até este ponto do texto pode-se ratificar o que Palharini apontava em seu texto de 1998, bem como tornar mais explícitos os "eixos norteadores" da produção acadêmica e o projeto político do NUPES.

Um primeiro aspecto que se põe em destaque é a confirmação do que já se observava em 1998, isto é, a produção do Núcleo é sempre focada no Brasil, mas contextualizada nas mudanças estruturais em curso no capitalismo mundial. Em acréscimo, tal contexto serve de base para as orientações da produção do referido órgão, bem como para os gestores públicos, especialmente a partir do governo de Fernando Henrique Cardoso. Destaca-se, ainda, que tal produção é parcialmente referenciada na realidade da América Latina e aí tem ancorado suas análises e proposições sobre as reformas em curso, especialmente a partir da segunda metade da década de 1990.

Outro traço distintivo da produção do NUPES é a equação que parece também ter orientado a criação da USP em 1934: a centralidade da ciência, da educação e da tecnologia para o desenvolvimento do país e o bemestar do cidadão. O desenvolvimento científico levaria a um incremento tecnológico, produzindo inovações tecnológicas e maior valor agregado aos produtos, o que fortaleceria a economia nacional, produzindo, dessa maneira, ações do Estado em prol do benefício da sociedade.

O terceiro traço constitutivo da produção do NUPES reside no seu campo teórico-metodológico, produzido pelos seus três principais pesquisadores, já mencionados no início deste texto, e que têm em Joseph BemDavid e Tacott Parsons seus maiores inspiradores, bastando para isto analisar as referências dos DTs do NUPES. Tal campo tem influências indiretas de Weber, traduzidas para o funcionalismo que predominou nos Estados Unidos nas décadas de 1950 e 1960. Segundo Marsal (2002) esta tradução apresenta-se de forma reducionista, porque descontextualizada das principais preocupações do pensador alemão: "o poder, ou seja, a política, a religião e o capitalismo, acompanhado tudo isso por um aparelho metodológico e científico que de modo algum pode separar-se daquelas preocupações valorativas fundamentais." (p. 16).

No campo educacional de nível superior, o NUPES apresenta justificativas teóricas que nos parecem estranhas em certos momentos, como procuramos demonstrar nos textos de Durham. A pesquisadora, gestora educacional em vários governos, entende que a educação superior pública 
tem custos muito elevados e não condizentes com a qualidade da docência, da pesquisa e da extensão, e que, portanto, não tem contribuído para a realização de sua teoria da centralidade da ciência, da tecnologia e da educação. Em razão disso, as produções indicam uma solução baseada num Estado forte e definidor de parâmetros para a educação, de forma centralizada, para que as instituições os realizem, sob o paradigma de um Estado avaliador por meio de um rígido sistema de exames para o setor público e/ ou para o privado. No caso da esfera pública, o financiamento seria condicionado à avaliação do Estado. Destaca-se, dada a orientação da produção do NUPES, que os parâmetros produzidos centralizadamente pelo Estado são de natureza mercantil e produzem a mercantilização como paradigma para a Educação Superior, provocando intensas mudanças no ethos das IES, que teriam mais as características de uma empresa prestadora de serviço do que de uma instituição educacional do terceiro grau. Disso decorrem dois outros traços perversos: a subordinação da universidade ao Estado e ao setor produtivo. O que implica dizer que a autonomia universitária é tutelada pelo Estado, de um lado, e, de outro, fica ao sabor das necessidades de um mercado organizado em âmbito globalizado, segundo a racionalidade do capitalismo contemporâneo.

Outra conseqüência do que até agora se expôs sobre a produção do NUPES, constitui-se na diversificação das fontes de financiamento para além do que o Estado provê, provocando uma enorme diferenciação institucional. $\mathrm{O}$ "incentivo às instituições de melhor desempenho em detrimento das de pior qualidade, públicas ou privadas". A diferenciação institucional traria graves conseqüências para o movimento docente, um grande defensor da escola pública em todos os seus níveis. Aliás, ele é tratado no âmbito da produção acadêmica do Núcleo como um movimento de base exclusivamente corporativa. Destaca-se, aqui, ainda, a acentuação do processo de mercantilização das IES por essa via.

Como se pode notar, a produção científica do Núcleo de Pesquisa sobre Ensino Superior com o objetivo de influir nas políticas públicas para Educação Superior parece defender, por meio da mercantilização desse nível educacional, uma nova institucionalidade para toda a sociedade, na qual os direitos sociais subjetivos dos cidadãos transformem-se em quase mercadoria, e a formação do sujeito fique subsumida ao trabalho socialmente necessário e abstrato, na medida em que contribui para a transformação da identidade das instituições de Educação Superior.

Por outro lado, é necessário indagar sobre a presença de seus pesquisadores principais assumindo postos-chaves em três governos seguidos, construindo estruturas para a reconfiguração da Educação Superior na di- 
reção referida. Tais intelectuais muito contribuíram direta ou indiretamente para a construção do Ordenamento Jurídico para a Educação Superior brasileira (SILVA JR; SGUISSARDI, 2001), ver especialmente o capítulo I) Se não para responder, pelo menos para lançar alguma luz sobre um possível itinerário desde a fundação do NUPES e sua ação em 1989 até o momento presente, é necessário compreender-se alguns condicionantes de nossa história recente, em particular, na produção do novo desenho da Educação Superior.

As construções de bases teóricas para a formulação de políticas públicas que tomam o objeto da política como um ente abstrato é procedimento filosoficamente idealista, que, na prática, significa a desconsideração da realidade social construída pelo ser humano, portanto trata-se de um movimento fortemente marcado por um viés totalitário, que parece ter marcado o NUPES, a SBPC, e, por especulação, o NUPPs. A história mostrará.

\section{O Ordenamento Jurídico Recente da Educação Superior no Brasil}

O ordenamento jurídico da Educação Superior, estruturado pela legislação e normas recentes, encontra na Lei 9.394/96 (Lei de Diretrizes e Bases da Educação Nacional) seu documento legal mais importante, especialmente no extenso e genérico capítulo Da Educação Superior. Depois de anos tramitando no Congresso Nacional, com base em um projeto que teve origem na sociedade civil, sendo discutido primeiramente na Câmara, e com base em outro, originário do Senado em articulação com o Executivo, nossa Lei maior para educação reduziu-se a um guarda-chuva genérico de natureza jurídica para dar guarida às ações do Ministério da Educação, seguindo as orientações contidas no documento que realmente orientou a reforma educacional brasileira no Brasil de FHC: Planejamento Político Estratégico do MEC (1995-1998). Este documento, aliás, induziu a própria lei referida (SILVA JR, 2003). Vale observar a versão da Lei aprovada no Senado, que tornava claro o propósito da diferenciação institucional, que organizava o campo da Educação Superior quanto ao seu desenho institucional da seguinte forma: universidades, centros de educação superior, institutos, faculdades e escolas superiores. Contudo, mas, na versão aprovada no Congresso, de forma genérica, no artigo 45, reduz-se a: "A educação superior será ministrada em instituição de ensino superior, públicas ou privadas, com variados graus de abrangência ou especialização." (SILVA JR; SGUISSARDI, 2001). Por outro lado, no que se relaciona à 
nova institucionalidade a que nos referimos, o Ministério da Reforma do Estado e da Administração Pública propunha a transformação das instituições federais de educação superior em fundações públicas de direito privado, as tão criticadas organizações sociais, o que permitiria estruturá-las segundo o direto privado. No artigo 54, a LDB abre uma brecha para tal mudança, ao assegurar que as universidades

gozarão, na forma da lei, de estatuto jurídico especial para atender às peculiaridades de sua estrutura, organização e funcionamento pelo Poder Público, assim como dos seus planos de carreira e do regime jurídico do seu pessoal [e, ainda] com o que prevê o inciso I do parágrafo $1^{\text {o }}$ "propor o seu quadro de pessoal docente e administrativo, assim como um plano de cargos e salários, atendidas as normas gerais pertinentes e os recursos gerais pertinentes e os recursos disponíveis.” (SILVA JR; SGUISSARDI, 2001, p. 54).

Estes dispositivos acentuam ainda mais a referida diferenciação institucional, bem como a diversificação de fontes de financiamento, comprometendo a autonomia universitária, de acordo com as orientações da produção acadêmica do NUPES. Além de acabar com a unicidade de carreira, estraçalha o Regime Jurídico Único, um "privilégio corporativo", segundo o que se lê na produção acadêmica do referido Núcleo, uma "ditadura dos funcionários" proporcionada pela burocracia de Estado, na suposta leitura de Weber. Na mesma direção da diferenciação institucional, a LDB é omissa quanto à indissociabilidade entre ensino, pesquisa e extensão, que só é exigida por meio do Decreto 2.306/97, que revoga o de n. ${ }^{\circ}$ 2.207/97, somente para as instituições organizadas sob a forma de universidades. O Decreto 2.306/97, dada a flexibilidade da LDB, permite ao Ministério da Educação, ancorado no Planejamento Político Estratégico do MEC (1995-1998), reformar a educação superior, introduzindo as distinções entre instituições públicas, instituições privadas sem fins lucrativos e instituições privadas com fins lucrativos. Em seu artigo $4 .^{\circ}$ deixa explícito o que o artigo 45 tenta escamotear:

Art. $4^{\circ}$. - Quanto à sua organização acadêmica, as instituições de ensino superior do Sistema Federal de Ensino classificam-se em:

I - universidades;

II - centros universitários;

III - faculdades integradas;

IV - faculdades isoladas;

V - institutos superiores ou escolas superiores. 
Com isso, depois de muito tempo, os formuladores de políticas para a Educação Superior conseguiam seu intento: diferenciar as "universidades de pesquisa" (centros de excelência) das "universidades de ensino", já presentes nas propostas do Grupo de Estudos para a Reestruturação do Ensino Superior, instituído pelo MEC em meados da década de 1980. Em acréscimo, a portaria 637/97, do MEC, estabelece uma norma draconiana para os procedimentos de credenciamento das IES das instituições privadas, que reivindicarem sua transformação em universidades, mantendo, no ordenamento jurídico, uma relação de identidade com as propostas derivadas da produção do NUPES.

Quanto à autonomia universitária, as propostas do MEC entraram em contradição com as propostas da reforma do Estado. É que este ministério insistia que as universidades seriam entidades de direito público, impossibilitando, dessa forma, a transformações das IFES em organizações sociais. Novamente, neste ponto, a LDB forneceu a âncora jurídica, posto que as instituições tornar-se-iam organizações sociais voluntariamente.

Silva Jr e Sguissardi (p. 62) escreveram:

O poder de cada universidade decidir autonomamente sobre sua política de pessoal, incluindo contratações e remunerações, foi incorporado ao Capítulo Da Educação Superior da LDB. Não menos significativo é o enunciado: As universidades serão estimuladas a buscar fontes adicionais junto a outras esferas do poder público e à iniciativa privada para ampliar o atendimento a outras demandas sociais que não o ensino.

Novamente o projeto político para a Educação Superior, do NUPES, manteve identidade com a nova base legal desse nível educacional, mostrando, mais uma vez, sua natureza política de produtor das bases teóricas para as Novas Faces da Educação Superior no Brasil, que expressam, nesse âmbito, a mesma matriz teórico-político-ideológica da reforma do Estado, que se processou sob a batuta de Bresser Pereira. Este, por sua vez, estava sob a orientação política de Fernando Henrique Cardoso, que, na sua prática, como Presidente do Brasil, aderiu aos ensinamentos dos organismos e agências multilaterais, numa espécie de atualização de sua Teoria da Dependência. Os governos de Fernando Henrique Cardoso marcaram uma ruptura, mas, ao mesmo tempo, muitas continuidades no que se refere à Educação Superior, o que é fundamental para compreendermos a identidade entre a existência do NUPES, sua produção e a ação na gestão estatal da Educação Superior no país, mudando a identidade das IES, bem como reconfigurando o espaço deste grau de ensino. 
Claro está que o processo de globalização do Capitalismo exigiu mudanças na forma de ser social. Isso exigiu um intenso processo de reformas institucionais para produzir nova estrutura social, nova cultura (formas de incorporação do que já fora produzido pela humanidade ao longo de sua existência) e novas políticas, sobretudo da educação em particular que, junto com o Estado, produz e reproduz a matriz teórica, política e ideológica, utilizando-se academicamente dos intelectuais da universidade e politicamente de associações científicas como a $\mathrm{SBPC}^{3}$. Assim à produção da ciência e às instituições que a produzem impõem-se as metas de um determinado governo, qualquer que seja sua orientação, tornando-se ambos profissionais e pragmáticos, contrariando a necessária identidade da Educação Superior com sua função social, o que provoca um ser social divisível, quando não individualista e possessivo.

Decorrente deste processo que, com a compressão espaço-tempo, acentua a alienação e intensifica as reformas, a saúde mental do professor da educação superior corre o risco de vir a ser, no limite, um grande problema de saúde pública do planeta, a começar pela esquizofrenia, bipolaridadade, alcoolismo, burnout, síndrome do pânico, depressão, fadiga intelectual, etc. Isto porque se caiu no ardil do produtivismo e do carreirismo: escrevem-se dez textos para fazer a crítica, mas se o faz; logo se faz o que se critica, curvando-se à persuasão e à coerção da avaliação eficientista.

\section{REFERÊNCIAS}

CAMPOS, Ernesto de Souza. História da Universidade de São Paulo. São Paulo: [s.n.], 1954.

CORAGGIO, José Luis. Propostas do Banco Mundial para a educação: sentido oculto ou problemas de concepção. In: HADDAD, Sérgio; TOMMASI Lívia de; WARDE, Mirian Jorge (Org.). O Banco Mundial e as políticas educacionais. São Paulo: Cortez, 1996.

DURHAM, Eunice Ribeiro. As políticas recentes para o ensino superior na América Latina. São Paulo: Universidade de São Paulo/NUPES, 1997. 17 p. (Documento de Trabalho 07/97).

A Pós-Graduação no Brasil: problemas e perspectivas. São Paulo: Universidade de São Paulo/NUPES, 1996. 21p. (Documento de Trabalho 08/96).

\footnotetext{
3 A SBPC, em face da transformação do NUPES em NUPPS, liderada pelo prof. Ênnio Candotti, acabou por assumir a paternidade de toda atividade do projeto mercantilista do NUPES. Lembre-se que os associados (institucionais) da SBPC são em sua esmagadora maioria sociedades científicas cujas bases encontram-se na esfera estatal pública. Intencionalmente ou não, a última gestão da SBPC "deu um tiro no pé", que atingiu de chofre a identidade da universidade pública e este mesmo grupo apóia o denominado Projeto Universidade Nova.
} 
DURHAM, Eunice Ribeiro. As universidades públicas e a pesquisa no Brasil. São Paulo: USP; NUPES, 1998, 36p. (Documento de Trabalho 09/98). FÀVERO, Maria de Lourdes de Albuquerque. Universidade e poder: análise crítica/fundamentos históricos: 1930-1945. Rio de Janeiro: Achiamé, 1980.

MARSAL, Juan F. Por que Weber? In: WEBER, Max. Ciência e política: duas vocações. São Paulo: Martin Claret, 2002.

PALHARINI, Francisco de Assis. Caderno NUPES: o novo protagonista na formulação teórica da política para o ensino superior. In: MOROSINI, Marília; SGUISSARDI, Valdemar. A educação superior em periódicos nacionais. Espírito Santo: FCAA/CNPq, 1998.

PREIRA, Luiz Carlos Bresser. Crise econômica e reforma do Estado no Brasil: para uma nova interpretação da América Latina. São Paulo: Editora 34, 1996. p. 7.

SADER, Emir. Público versus mercantil. Folha de S. Paulo, São Paulo, 19 jun. 2003. p. 3.

SAMPAIO, Helena. Universidades privadas: características institucionais e acadêmicas. São Paulo: Universidade de São Paulo/NUPES, 1998. 53 p. (Documento de Trabalho 12/98).

. Setor privado de ensino superior no Brasil: atores e policies. São Paulo: Universidade de São Paulo/NUPES, 1998. 61 p. (Documento de Trabalho 7/98).

SCHWARTZMAN, Simon. Relatório de uma Visita ao Brasil Universidade e Ciência por Ben-David. (Introdução ao Texto de BenDavid). Ciência Hoje, Rio de Janeiro, v. 7, n. 37, nov. 1987, p.68.

Disponível em: <http://www.schwartzman.org.br/simon/publicac.htm>. Acesso em: maio 2000.

SGUISSARDI, Valdemar; SILVA JR, João dos Reis. Construindo fontes de dados e uma agenda de pesquisa: O Banco de Dados Universitas $/ B r$. Comunicações, Piracicaba, SP, UNIMEP, Ano 9, p. 21-43, jun. 2002. SGUISSARDI, Valdemar; SILVA JR, João dos Reis. Educação superior: análise e perspectivas de pesquisa. São Paulo: Xamã, 2001.

SGUISSARDI, Valdemar; SILVA JR, João dos Reis. Educação brasileira no Século XXI - entre a cultura do medo e a busca de liberdade. Impulso, Piracicaba, SP, v. 16, n. 40, p. 11-18, 2005 b.

SILVA JÚNIOR, João dos Reis da. Reforma do Estado e da educação no Brasil de FHC. São Paulo: Xamã, 2002.

SILVA JUNIOR, J. R.; SGUISSARDI, Valdemar. A nova lei de educação superior: fortalecimento do setor público e regulação do privado/mercantil ou continuidade da privatização e mercantilização do público?. Revista Brasileira de Educação, Rio de Janeiro, v. 27, p. 5-27, 2005 a. 